\title{
Correlation analysis for adoption studies of rice growers in district Baramulla of Kashmir Division, India
}

\section{Maddina Sreekanth}

Division of Agriculture Extension and Communication, Faculty of Agriculture, SKUAST-K (J\&K), India

\section{Quadri Javeed Ahmad Peer *}

Division of Agriculture Extension and Communication, Faculty of Agriculture, SKUAST-K (J\&K), India

Sajad.A.Saraf

Division Agriculture Economics, Faculty of Agriculture, SKUAST-K (J\&K), India

N. A. Ganai

Division of Horticulture Faculty of Agriculture, SKUAST-K (J\&K), India

*Corresponding author. E-mail: qadrijavid2008@gmail.com

\section{Abstract}

This study about the correlation analysis for adoption and knowledge of rice growers was carried in 12 randomly selected villages of 3 tehsils prominently growing rice of district Baramulla of J\&K state. After multi-stage random 10 rice growers from each village were selected randomly and systematic sampling technique a sample of 120 rice farmers was drawn. It was found that Knowledge were found positively correlated with Education (0.449) Occupation (0.356), Social participation (0.205), annual income (0.229), Mass media exposure $\left(0.375^{)}\right.$, Extension contacts $\left(0.219^{)}\right.$and Scientific orientation $\left(0.341^{\prime}\right.$ and Adoption were also found positively correlated with Education $(0.447)$ Occupation (0.348), Social participation (0.301), Annual income (0.243), Mass media exposure (0.309), Extension contacts $(0.243)$ and Scientific orientation (0.338) whereas Age, Family size, Land holding and Farming experience have no significance with knowledge and adoption level of famers. The significance at 0.01 level of variables like Education, Occupation, Social Participation, Annual income, Mass Media Exposure, Extension contacts and Scientific Orientation with dependent variable Knowledge and adoption level of rice growers. The results of the study indicated that these selected variables might play a very important role in increasing the Knowledge and adoption level of the package of practices by rice growers of Kashmir Division.

Keywords: Adoption, Correlation, Knowledge, Rice growers

\section{Article Info}

https://doi.org/10.31018/

jans.vi.2246

Received: March 27, 2020

Revised: April 18, 2020

Accepted: May 8, 2020

\section{How to Cite}

Sreekanth, M. et al. (2020) Correlation analysis for adoption studies of rice growers in district Baramulla of Kashmir Division, India . Journal of Applied and Natural Science, 12 (2): $98-100$ https://doi.org/10.31018/ jans.vi.2246

\section{INTRODUCTION}

Rice production in the Jammu and Kashmir (J\&K) is predominantly a mono cropped activity with very high consumption and most important staple food than other states of India. The area under the rice is distributed by both the regions in which about $40 \%$ of production is from Jammu division while as $60 \%$ from Kashmir division (DES,2016a). Rice plays an important role in the livelihood of the people in the state, although the area under the crop is very small as compared to other states of India with only $0.30 \mathrm{~m}$ hectare area, at the same time plays an important role in the state economy (Economic Survey, 2016). Rice will remain an important and staple food for the people of Jammu \& Kashmir. However, there has been a considerable decrease in area under paddy cultivation in Kashmir valley due to switching over to horticulture crops, particularly apple orchards besides housing and developmental projects. Though, the productivity levels got improved over time still, the gap of self-sufficiency is widening which is evident from the growing import and offtake of rice stocks and burgeoning rationed population under PDS system of the state (Farhet et al.,2018). In District Baramulla the rice cultivated area has increased from 8094 to 8514 hectares and the production from 194.39 to 144.39 thousand metric tonnes has decreased during the year 2011-12 to 2014-15 respectively (DES, 2016b). It has been found that the production and productivity levels over the decade has fallen due to poor 
and deteriorating soils. The probable reason for this might be due to poor knowledge and adoption level of farmers about package of practices. The knowledge and adoption levels of respondents are mostly influenced by personal, socio-economical, psychological and communication characteristics of individuals. In this contest a study on the relation of farmer's selected characteristics with their Knowledge and Adoption of Rice Cultivation practices has been taken with the objectives-i) Correlation of selected profile characteristics of rice growers with their knowledge, ii) Correlation of selected profile characteristics of rice growers with their adoption.

\section{MATERIALS AND METHODS}

The research study was conducted purposefully in the Sopore, Patten and Bomai tehsil of Baramulla District of Jammu and Kashmir. The twelve villages were selected randomly from these tehsils for the present study. After multi-stage random sampling, 10 rice growers from each village were selected and data were collected from 120 respondents by personal interview method containing questions which were retained after putting them to discrimination and difficulty Index. Eleven independent variables, i.e. Age, Family size, Landholding and Farming experience, Education, Occupation, Social Participation, Annual income, Mass Media Exposure, Extension contacts and
Scientific Orientation were subjected to statistical analysis for the purpose of studying their relationship with two dependent variables knowledge and adoption.

Correlation coefficient ( $r$-value): It is to find out the relationship between independent and dependent variables and was calculated by employing the following formula suggested by Karl Pearson.

$\sum X i Y i-\frac{\sum(X) \sum(y)}{n}$

$$
\begin{aligned}
& \mathrm{r}=\frac{\left.\sum \mathrm{Xi}_{2_{-}} \sum(\mathrm{x})^{2}\right]\left[\mathrm{Yi}_{2}-\sum(\mathrm{y})^{2}\right]}{\mathrm{H}^{2}} \\
& n \quad n
\end{aligned}
$$

Where, $\mathrm{n}=$ Number of respondents

$\Sigma X i Y i=$ sum of product $X$ and $Y$

$X$ and $Y=$ Dependent and independent variables correlated

$\Sigma X=$ Summation of overall dependent variables $\sum Y=$ Summation of overall independent variables $\mathrm{X}^{2}=$ Sum of all squared values of dependent variables

$\mathrm{Y}^{2}=$ Sum of all values of independent variables

\section{RESULTS AND DISCUSSION}

In order to study the nature of relationship between the selected profile characteristics of rice growers and their level knowledge and adoption, correlation analysis was followed using standard

Table 1. Relationship of independent variables of respondents with their knowledge $(N=120)$.

\begin{tabular}{llcc}
\hline S.N. & \multicolumn{1}{c}{ Variable } & $\begin{array}{c}\text { Correlation coefficients } \\
\text { ('r' Value) }\end{array}$ & 'p' Value \\
\hline 1 & Age & 0.054 & 0.556 \\
2 & Education & $0.449^{* *}$ & 0.000 \\
3 & Family size & 0.063 & 0.496 \\
4 & Occupation & $0.356^{* *}$ & 0.000 \\
5 & Land holding & 0.150 & 0.103 \\
6 & Farming Experience & 0.079 & 0.390 \\
7 & Social Participation & $0.205^{* *}$ & 0.000 \\
8 & Annual Income & $0.229^{*}$ & 0.012 \\
9 & Mass Media Exposure & $0.375^{* *}$ & 0.000 \\
10 & Extension contacts & $0.219^{*}$ & 0.016 \\
11 & Scientific Orientation & $0.341^{* *}$ & 0.000 \\
\hline
\end{tabular}

**Significant $p \leq 0.01$ level of probability and *Significant $p \leq 0.05$ level of probability

Table 2. Relationship of independent variables of respondents with their adoption $(N=120)$.

\begin{tabular}{llcc}
\hline S.No. & \multicolumn{1}{c}{ Variable } & $\begin{array}{c}\text { Correlation coefficients } \\
\text { ('r' Value) }\end{array}$ & ' $p^{\text {' Value }}$ \\
\hline 1 & Age & 0.048 & 0.600 \\
2 & Education & $0.447^{* *}$ & 0.000 \\
3 & Family size & 0.168 & 0.067 \\
4 & Occupation & $0.348^{* *}$ & 0.000 \\
5 & Land holding & 0.047 & 0.612 \\
6 & Farming Experience & 0.084 & 0.364 \\
7 & Social Participation & $0.301^{* *}$ & 0.000 \\
8 & Annual Income & $0.243^{* *}$ & 0.008 \\
9 & Mass Media Exposure & $0.309^{* *}$ & 0.001 \\
10 & Extension contacts & $0.243^{* *}$ & 0.007 \\
11 & Scientific Orientation & $0.338^{* *}$ & 0.000 \\
\hline
\end{tabular}

**Significant $p \leq 0.01$ level of probability and *Significant $p \leq 0.05$ level of probability 
statistical package (SPSS).

Correlation of independent variables with the knowledge level of rice growers: The results in the Table 1 showed that out of 11 variables 7 variables had shown a significant relationship with the knowledge level of rice growers in which 6 variables namely Education, Occupation, Social Participation, Mass Media Exposure, Extension contacts and Scientific Orientation had shown significance at 0.01 level whereas Annual income had significance with knowledge at 0.05 level. The non -significant relationship of Age, Family size, Land holding and Farming experience with knowledge was observed in the present study. The significant correlation co-efficient of independent variables Education, Occupation, Social Participation, Annual income, Mass Media Exposure, Extension contacts and Scientific Orientation with dependent variable Knowledge level of rice growers indicated that these selected characteristics played very important role in increasing the knowledge level of rice growers. The findings of family size are not in line with findings of Sunil (2017). Who found that the family size of the respondents has no significant relationship with the knowledge of farming practices in existing farming systems of northern hills of Chhattisgarh.

Correlation of independent variables with adoption level of rice growers: The results in the Table 2 depicted that out of 11 variables 7 variables had shown significant relationship with adoption level of rice growers in which 6 variables namely Education, Occupation, Social Participation, Mass Media Exposure, Extension contacts and Scientific Orientation had shown significance at 0.01 level whereas Annual income had significance with knowledge at 0.05 level. The nonsignificant relationship of Age, Family size, Land holding and Farming experience with adoption level was observed in the present study. From the findings we can interpret that independent variables Education, Occupation, Social Participation, Annual income, Mass Media Exposure, Extension contacts and Scientific Orientation play a pivotal role in increasing the adoption level of package of practices by rice growers. The findings of land holding are not in line with findings of Sunil (2017). Who found that the land holding of the respondents has no significant relationship with the adoption level of farming practices in existing farming systems of northern hills of Chhattisgarh.

\section{Conclusion}

The present study concluded that knowledge and adoption were found positively correlated with Education, Occupation, Social participation, annual income, Mass media exposure, Extension contacts and Scientific orientation whereas Age, Family size, Land holding and Farming experience had no significance with knowledge and adoption level of famers. The significance of the correlation coefficient to decide the strength of the linear relationship between dependent and independent variables. The results of study revealed that there is sufficient evidence to conclude that there is a significant relationship between two types of variables.

\section{REFERENCES}

1. DES (2016a). Directorate of Economics and Statistics, Planning and Development Department, Statistical Digest 2015-16, Jammu and Kashmir, Accessed at http://ecostatjk.nic.in/ publications / publications.htm.

2. DES (2016b). Directorate of Economics and Statistics, 2015-2016 (url: http//agricoop. nic. in). Economic Survey, Government of Jammu and Kashmir, 201314, Assessed from url: http//www. Indiaenviron mentportal. org. in.

3. Economic Survey (2016). Directorate of Economics and Statistics, Planning and Development Department, Jammu and Kashmir, Accessed at http:// ecostatjk.nic. in/ publications /publications.htm.

4. Farhet A. Shaheen, Shabir A. Wani, G.A. Parray, N.R. Sofi, M. Anwar Bhat, Tariq Sultan, F.A. Mohiddin Shahid Jibran, Naseem Akhter, Farheen Naqash and Faheem Jeelani (2018). Sustaining Rice Farming in Kashmir Valley: Challenges and Opportunities . Agro Economist An International Journal Citation: AE: 5(2): 61-70

5. Sunil, N. (2017). A study on identification, Characterization and adoption pattern of Farm practices in existing farming systems of northern hills of Chhattisgarh. Ph. D. Thesis. Indira Gandhi Krishi Vishwavidyalaya, Raipur. 